\title{
LIQUIDITY COSTS IN EMERGING CORN FUTURES MARKETS
}

\section{JULYERME MATHEUS TONIN}

Universidade Estadual de Maringá (UEM), Maringá - PR - Brazil.

GERALDO COSTA JUNIOR

Universidade Federal Fluminense (UFF), Macaé - RJ - Brazil.

JOÃO GOMES MARTINES FILHO

Universidade de São Paulo (USP), Piracicaba - SP - Brazil.

To cite this paper: Tonin, J. M., Costa Junior, G., \& Martines Filho, J. G. (2017). Liquidity costs in emerging corn futures markets. Revista de Administração Mackenzie, 18(6), 201-223. doi 10.1590/167869712017/administracao.v18n6p201-223

\section{ACKNOWLEDGEMENTS}

Thanks to the anonymous reviewers for their careful reading of the manuscript, insightful comments, and suggestions. 


\section{ABSTRACT}

Objective: The present study estimates the liquidity cost of the corn future contract traded on B3 (formerly BM\&FBovespa) and compare it to the CME corn future contract, through five implicit bid-ask spread measures.

Originality/value: The market microstructure approach, with its focus on high frequency data, reveals characteristics of the emerging agricultural markets (also known as thin markets), which were not evident in studies with daily frequency data.

Design/methodology/approach: To analyze the performance of five cost estimators, the data used in our analysis consists of intraday series of future contracts of B3 and CME from September 1, 2015, to August 30, 2016. The methodology adopted includes these estimators: Roll model (1984); Model of Thompson \& Waller (1987) model of Choi, Salandro \& Shastri (1988); Model of Chu, Ding \& Pyun (1996) and the model of Wang, Yau \& Baptiste (1997).

Findings: The liquidity cost is lower in CME's future corn market than in B3, and the estimated cost of liquidity in CME's future corn market is 2 to 3 cents (in $\mathrm{R} \$ / 60-\mathrm{kgbag}$ ) while at $\mathrm{BM} \& \mathrm{~F}$ the cost is 6 to 16 cents (in $\mathrm{R} \$ / 60-\mathrm{kgbag}$ ).

\section{KEYWORDS}

High frequency Data. Bid-ask spread. Futures market. Corn market. Commodities.

\section{INTRODUCTION}

Corn production plays a strategic role in the Brazilian agribusiness industry. The existence of two harvests a year reinforces its importance in 
terms of food safety, and amplifies the linkage with other sectors, such as poultry and swine. USDA (2017) ranks Brazil among the three largest corn producers, and the estimates for the $2016 / 2017$ harvest point to an increase in both production ( 98.50 million tons) and planted area (17.55 million hectares). However, in a broader perspective, Brazilian corn production is still small, accounting for approximately $9 \%$ of the global corn production. Like other crops, the agents involved in corn production are exposed to the risk of price volatility (Gaudenzi et al., 2017).

The main sources of instability of agricultural prices are related to the climate, incidence of pests and diseases, international market dynamics and exchange rates. In this context, to attain adequate price risk management, it is necessary to use risk mitigation tools, such as derivative contracts. Thus, the study of agricultural futures markets contributes to its organization and efficiency, and is beneficial to farmers, market participants, policymakers, and other agents operating in the industry. In addition, the use of agricultural markets is crucial for Brazil, due to its prominent role in the production and export of agricultural commodities.

However, over the last decade, structures, technologies, and regulations introduced in exchanges around the world have triggered unprecedented transformations in financial markets. The introduction of electronic trading platforms contributed to the diversification of financial instruments, market participants, and ultimately led to higher levels of traded volume (Irwin \& Sanders, 2012). In this context, pressing issues in financial economics, such as price formation, price discovery, liquidity, market transparency, behavior of traders, and information flow must be reevaluated.

In this new context, we use the market microstructure approach to proceed our analysis. Focusing on high frequency data, market microstructure models provide a more detailed analysis since they reveal certain aspects that have not evident in studies with daily, weekly or monthly data. Studies related to the microstructure of agricultural futures markets are still scarce (Bryant \& Haigh 2004; Eaves \& Williams, 2010; Frank \& Garcia 2011; Martinez, Gupta, Tse, \& Kittiakarasakun, 2011; Shah, Brorsen, \& Andersen, 2012; Irwing, 2014). The scarcity of studies in the area is accentuated in emerging agricultural markets, which often lack organized data or have low liquidity levels (thin markets). Brazil is possibly an exception to this rule since it has high quality data and relatively liquid commodities futures markets.

We choose the corn futures contract traded at Brasil Bolsa Balcão - B3 (former BM \& F-Bovespa) because of its relatively high and growing liquidity levels. Among the agricultural contracts traded at B3, the corn contract is 
the most liquid one, with 741,933 contracts traded in 2016 (B3, 2017). In addition, to understand the behavior of liquidity costs of corn futures better, in our analysis, we include the corn contracts traded at the Chicago Board of Trade (CBOT), a member of the CME Group, which is known for its very liquid corn futures markets, and is a good example of how corn futures markets should work.

By using B3 and CBOT intraday data, this paper aims to estimate and compare the liquidity costs related to the corn futures markets in B3 and CBOT. Another goal for this paper is to compare the performance of five bid-ask spread estimation models in markets with different levels of liquidity. There is a considerable number of papers exploring the analysis of liquidity costs for Brazilian stock and equities markets, but studies focusing on agricultural futures markets are still scarce (Marquezin \& Mattos, 2014). In addition, this paper innovates in measuring the performance of different the bid-ask spread estimation models in the context of mature (CBOT) and emerging markets (B3).

The remainder of this paper is organized as follows: section 2 presents the theoretical models that gave rise to the development of liquidity cost estimators; section 3 deals with the models that will be used in our estimates, namely the Roll model (1984); the Thompson and Waller (1987) model; the Choi, Salandro, and Shastri (1988) model; the Chu, Ding, and Pyun (1996) model, and the Wang, Yau, and Baptiste (1997) model; section 4 presents the database; in section 5 , we discuss the results obtained from the previously mentioned models and proceed the comparative analysis between the B3 and CBOT corn futures markets; section 6 concludes this paper.

\section{LITERATURE REVIEW}

The increasing availability of high frequency data has contributed to broaden and enhance market microstructure analysis. In its early days, the market microstructure field turned to the study of calendar effects and the identification of abnormal patterns in returns series (Wood, McInish, \& Ord 1985; Foster \& Viswanathan, 1990). Subsequently, a number of issues, such as information asymmetry, liquidity and private information, were incorporated into the analysis in an effort to understand the details of the agents' decision-making process better (Admati \& Pfleiderer, 1988).

The definition of liquidity gained importance in the market microstructure approach since market participants wish to trade in efficient and liquid 
markets, where they can trade in a low transaction costs environment. In this context, liquidity can be defined as the possibility of trading a certain asset, timely and in large volumes, at the prevailing market price. Low liquidity provides serial dependence on successive price changes, both because of the size and the direction of the last trade, which makes prices more volatile or abrupt (Roll, 1984).

In this direction, liquidity can be evaluated in three areas: i) thinness, which represents the difference between the current and the actual prices, as measured by the bid-ask spread; ii) depth, which shows the volume that can be traded at the current price level; and iii) resilience, which represents the speed of convergence to the price level after a random shock (Kyle, 1985). In this context, Demsetz (1968) was one of the first to introduce tools to gauge the bid-ask spread (BAS). In its most common definition, BAS is the difference between the ask price and the bid price for financial asset transactions at short intervals:

$$
\text { BAS = Ask Price }- \text { Bid Price }
$$

Despite the simple definition, the bid-ask spread can be useful in analyzing the impact of information on the market price, including its arrival, dissemination and processing. In this context, the bid-ask spread can be defined as a mark-up required for the existence of immediate buy and sell offers in the market (Demsetz, 1968). The bid-ask spread is certainly related to traded volume, since the frequency of transactions is a major factor that contributes to reduce bid-ask spread levels (Roll, 1984). The bid-ask spread also incorporates the effect of introducing a new buy or sell order in any given market (Thompson \& Waller, 1987).

According to Demsetz (1968), a market participant may try to sell (buy) the asset $\mathrm{X}_{\mathrm{i}}$, with supply curve $\left(\mathrm{S}_{\mathrm{i}}\right)$, demand curve $\left(\mathrm{D}_{\mathrm{i}}\right)$, equilibrium point $\left(E_{i}\right)$, and may not find a buyer (seller) immediately. In this situation, the lower the number of transactions, the longer the time required for buyers and sellers to meet in the market, i.e., the higher the liquidity cost. In the meantime, there are market makers who hold buy and sell offers in the market during the entire trading period, and to cover their transaction costs, they sell at slightly higher prices (the Supply Curve $S_{i}^{\prime}$ ), or buy at slightly lower prices (Demand Curve $D_{i}^{\prime}$ ). The difference between the prices in each situation $\left(A_{i}\right.$ and $\left.B_{i}\right)$ is the bid-ask spread, and the larger the spread, the higher the transaction cost (Figure 1). 


\section{(Figure 1)}

\section{SUPPLY AND DEMAND REPRESENTATION FOR THE BID-ASK SPREAD}

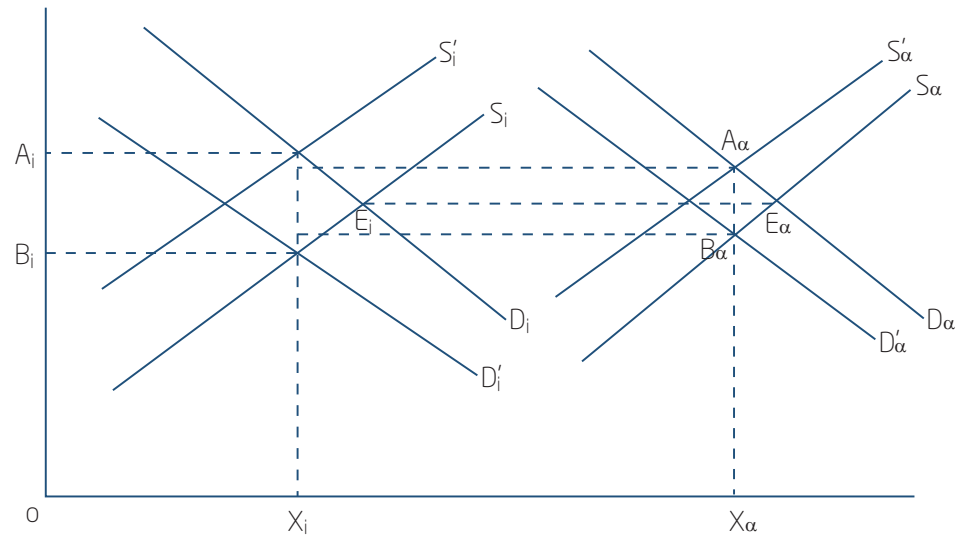

Source: Demsetz (1968, p. 38).

In the literature, Admati and Pfleiderer (1988) state that a U-shaped pattern would describe the intraday bid-ask spread behavior, relating higher volumes of negotiations to lower levels of BAS. However, Subrahmanyam (1991) demonstrated the possibility of coexistence of large trading volume and high bid-ask spread levels. Eaves and Williams (2010) demonstrated that the U-shaped pattern in intraday price behavior of financial series tends to become a L-shape in agricultural commodities price series. Lehecka et al. (2014) analyzed the intraday patterns of the corn futures market at the Chicago Board of Trade (CBOT) and found a reverse J pattern for the intraday volatility series of returns and a U-shape for the intraday volume series. Although the relationship between bid-ask spread and trading volume is a controversial point in the literature, BAS is the most popular proxy in the literature for the agents' liquidity cost.

Little attention has been given to this kind of analysis in agricultural futures markets. In this context, Thompson, Eales and Seibold (1993) found higher liquidity costs and smaller trading volumes in the wheat futures market in the less liquid Kansas City exchange, when compared to the more liquid Chicago exchange. On the other hand, Wang, Yau and Baptiste (1997) reported a negative relation between volume and volatility and between bidask spread and volatility in agricultural futures markets. In addition, the authors found that the volume traded in agricultural futures contracts is more inelastic to transaction costs than other contracts analyzed, which is justified by the lack of substitute agricultural contracts in other markets. 
Bryant and Haigh (2004) estimated the bid-ask spread for the cocoa and coffee markets in the International Commodities Exchange (ICE) and pointed to an increase in transaction costs after the implementation of electronic trading, due to increased volatility and adverse selection brought by electronic markets. On the other hand, Martinez et al. (2011) analyzed liquidity levels in the soybeans, wheat and corn futures markets at CBOT, while Shah and Brorsen (2011) evaluated the wheat futures market at the Kansas City Board of Trade before and after the introduction of electronic trading platforms. In both cases, the authors compared the contracts negotiated via electronic and outcry trading, and their conclusions pointed to higher transaction costs in the outcry trading system.

Frank and Garcia (2011) measured the liquidity cost in the CBOT cattle and hog futures markets. They found lower liquidity cost for the cattle contracts because of its higher trading volume, lower volatility, and because of the introduction of electronic trading. Shah, Brorsen, and Andersen (2012) analyzed wheat futures and options markets in Kansas City and found lower liquidity cost for the futures market in comparison to the options market.

Regarding Brazilian markets, Marquezin (2013) analyzed liquidity costs related to the soybean futures markets at B3 from 2010 to 2013. The results indicated that the liquidity costs found in the soybean futures market at B3 were still comparable to other soybean futures markets around the world. Marquezin \& Mattos (2014) analyzed the live cattle futures contracts at B3 and concluded that the maturity day exerted influence on the liquidity cost of these contracts.

\section{METHODOLOGY}

The bid-ask spread has become a popular and important tool to evaluate liquidity costs because it incorporates aspects related to traded volume, number and type of market participants, risk premium, among others. However, in some situations, the bid, the ask or both prices may not be promptly available. To overcome this problem, an implicit measure for the estimation of the bid-ask spread was developed by Roll (1984), which inaugurated a bid-ask spread study area based on price covariance.

In this context, the author established the following assumptions: 1. the market is efficient and all relevant information is included in the market price, 2. there is no serial dependence on successive price changes (other than that generated by serial dependence on expected returns). Such assumptions put 
the underlying real value of a financial asset at the center of the bid-ask spread, and the transaction values - bid or ask - are symmetric around this equilibrium price. Thus, in face of the emergence of information not anticipated by the market, both bid and ask prices move in a random and independent way (Roll, 1984).

In a situation where there is no new information coming to the market, changes in prices are stationary in the short run and transactions occur randomly based on the bid and ask prices. In this hypothetical situation, calculating the joint probability of price changes depends on whether the last transaction has been made on the bid or ask side. Starting from the situation where the market maker trades in its bid and assuming that successive transactions (bid or ask) are equally likely, we have:

\section{(figure 2)}

\section{POSSIBLE PRICE TRAJECTORIES PROPOSED BY ROLL (1984)}
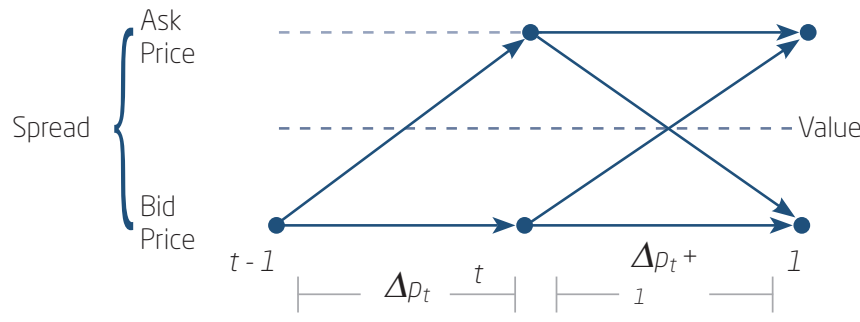

Source: Roll (1984, p. 1128)

In Figure 2, Roll (1984) states that if the transaction starts at bid (ask), there will be no possibility for the next transaction to occur below (above) this price either because there is no new information coming to the market or because it does not contemplate the possibility of two consecutive increases (decreases) in prices. Since the price trajectories from period $t$ are diametrically opposite, we obtain the probability distribution in two parts, depending on the occurrence of bid or ask in period $t$ - 1 . Therefore, the joint probability is calculated by incorporating all possible results into the analysis, and subsequently calculating the covariance between successive price changes, given by:

$$
\operatorname{Cov}\left(\Delta P_{t} ; \Delta P_{t+1}\right)=\frac{1}{8}\left(-s^{2}-s^{2}\right)=-\frac{s^{2}}{4}
$$


Rearranging equation (2):

$$
s^{R M}=2 \sqrt{-\operatorname{Cov}\left(\Delta P_{t} ; \Delta P_{t+1}\right)}
$$

The hypotheses made by Roll (1984) assure that the conditional probability for a transaction in $t+1$ to occur in bid (ask) given the occurrence of ask (bid) is always equal to the current transaction. In this context, Choi, Salandro, and Shastri (1988) abandon the hypothesis of non-serial dependence between successive price changes and adopt conditional probabilities that evolve according to a first-order Markov chain. However, relaxing the basic model hypothesis creates the need to know the buy and sell offers that originated the transaction, what may jeopardize the results of the model when offers are unknown.

To overcome this problem, Lee and Ready (1991) developed an inference rule or tick test to classify bid or ask operations based on the price direction of trades. The authors' criterion is to classify trades in: 1. uptick, if the current price is higher than the previous price $\left(P_{t}>P_{t-1}\right)$ and downtick, otherwise $\left(P_{t}<P_{t-1}\right) ; 2$. zero-uptick, if current and previous prices are equal, and the last observed price change was a price increase $\left(P_{t}=P_{t-1}\right.$ and $\left.P_{t-1}>P_{t-2}\right)$, zero-downtick, otherwise $\left(P_{t}=P_{t-1}\right.$ and $\left.P_{t-1}<P_{t-2}\right)$. Therefore, a negotiation is classified as bid, when it is uptick and zero-uptick, and as ask otherwise.

As the definition of conditional probability depends on the tick test, which incorporates two periods in the analysis prior to the evaluated negotiation, Chu, Ding, and Pyun (1996), developed a model capable of incorporating a second-order Markov chain in the analysis. Based on the conditional probability tree for the classification of bid or ask operations (Figure 3), it is possible to deduce the bid-ask spread as proposed by Choi, Salandro, and Shastri (1988) and Chu, Ding, and Pyun (1996). 


\section{(Figure 3)}

\section{PROBABILITY TREE DIAGRAM FOR THE DEFINITION OF THE BID-ASK SPREAD}

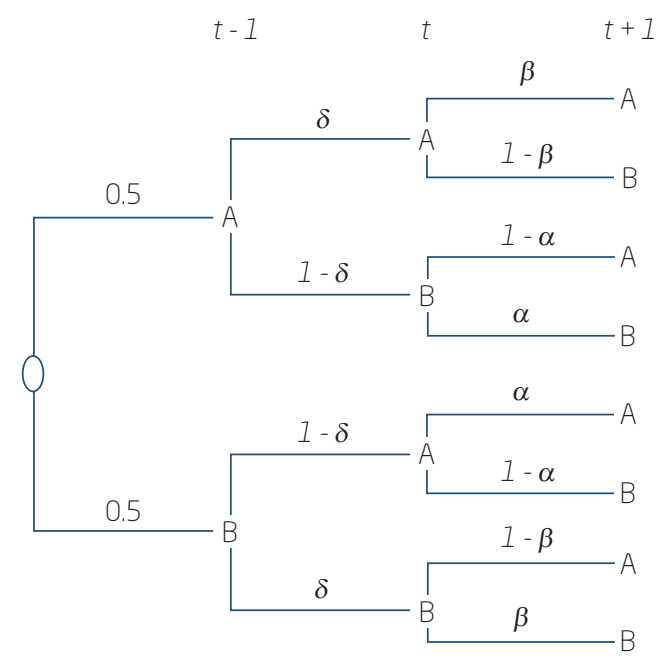

Source: Adapted from Chu, Ding, and Pyun (1996).

In this direction, the Choi, Salandro and Shastri (1988) model can be presented as:

$$
s^{\operatorname{CSS}}=\frac{\sqrt{-\operatorname{Cov}\left(\Delta P_{t} ; \Delta P_{t+1}\right)}}{(1-\delta)}
$$

When $\delta=0,5$, we have $s^{R O L L}=s^{C S S}$ and $\delta$ represents the conditional probability of occurrence of a bid (ask).

The Chu, Ding, and Pyun (1996) model is defined as:

$$
s^{C D P}=\frac{\sqrt{-\operatorname{Cov}\left(\Delta P_{t} ; \Delta P_{t+1}\right)}}{(1-\delta)(1-\alpha)}
$$

When $\alpha=\delta, s^{C S S}=s^{C D P}$ and when $\alpha=\delta=0,5, s^{R O L L}=s^{C S S}=s^{C D P}$.

Thompson and Waller (1987) introduced the analysis of series of variations in absolute prices. When estimating the execution cost of a transaction, the authors deduced a proxy for the bid-ask spread calculation. Assuming that the probability of occurrence of a price increase, a price decrease or no price change after a new market order is equally likely to 
happen, the liquidity cost can be obtained from the average absolute value of price variation. Thus, the magnitude of the price change can be used as proxy for the bid-ask spread.

$$
T W=\frac{1}{T} \sum_{t}^{T}\left|\Delta P_{t}\right|
$$

Where $\Delta P_{t}$ is an intraday series of non-zero price changes.

In the Wang, Yau, and Baptiste (1997) model, hereinafter referred to as the CFTC model, the Thompson and Waller (1987) approach is broadened to capture the relationship between price variation $\left(\Delta P_{t}\right.$ and $\left.\Delta P_{t-1}\right)$, in which there has been a price reversion. Thus, situations, in which a positive (negative) variation is succeeded by another positive (negative) variation, this observation is discarded in the estimation of the average of the absolute values.

$$
\text { CFTC }=\frac{1}{T} \sum_{t}^{T}\left|\Delta P_{t}^{*}\right|
$$

Where $\Delta P_{t}^{*}$ is an intraday series of non-zero price changes, in which prices necessarily have opposite signals.

According to Wang, Yau, and Baptiste (1997), this adaptation is useful as long as it focuses the analysis on the sources of volatility in the intraday price series. Thus, it is possible to assess the situations in which informed traders negotiate in the market more accurately, what gives an appropriate measure of market risk as well. In addition, the Thompson and Waller (TW) model is the only one that uses all available informational content.

For models based on covariance (RM, CSS and CDP), in situations where there is a positive covariance between price changes $\left(\Delta P_{t} ; \Delta P_{t+1}\right)$, it is not possible to obtain an analytical solution. On the other hand, the Wang, Yau, and Baptiste model (CFTC), considers only moments in which there is price reversion. In this direction, Otsubo (2015) discusses the existence of a potential bias in this indicator.

In the 1990s, the advances in information technology contributed to boost the availability of financial market data. In this direction, the calculation of the bid-ask spread started to be made from the buy and sell offers series. In this context, the quoted bid-ask model, in absolute terms, is described by Michaely and Vila (1996) as:

$$
A Q S_{t}=\frac{1}{T} \sum_{t}^{T}\left|\frac{A s k_{i j}-B i d_{i j}}{\left(A s k_{i j}+B i d_{i j}\right) / 2}\right|
$$


Where $A Q S_{t}$ represents the Absolute Quoted Spread in period $t$; and bid and ask will be calculated for $i$ days, in averaged values and $j$ maturities, and later grouped in averaged values for $t$ months.

It should be noted that despite of the greater availability of data, bid-ask spread measures based on covariance or absolute price variation are useful for thin markets analysis. Therefore, this paper aims to compare the price covariance models (ROLL, CSS, CDP), the absolute price variation models (TW and CFTC) and the quoted bid-ask spread (AQS). Furthermore, we evaluate which of the models captures the bid-ask spread behavior in the Brazilian corn futures market better and verify whether any difference can be found between the corn futures markets at B3 and CBOT.

\section{DATABASE}

Our database is composed of intraday price and volume series of corn futures contracts traded at B3 (formerly BM\&FBovespa) in $\mathrm{R} \$ / \mathrm{kg}$ of $60 \mathrm{~kg}$ and on the Chicago Board of Trade (CBOT), in US\$/bushel. We obtained our data from the Bloomberg ${ }^{\circledR}$ vendor, for the period from September 1, 2015 to August 30, 2016. For the purpose of comparing the results in each stock exchange, CBOT prices were converted to $\mathrm{R} \$ / \mathrm{bag}$ of $60 \mathrm{~kg}$.

We collected the averaged values of the ticks traded in 5-minute periods, excluding trading intervals in which no transaction was performed. We gathered 136,226 observations in the CBOT and 25,490 observations in the B3. After the estimation of the auto-covariance between the prices of intraday transactions, the daily spreads were obtained, which were then grouped into monthly estimates for each maturity. The average values of bid and ask for the 5-minute series were used to calculate the quoted bid-ask spread, which was used as a reference for the other models. For the models based on covariance between price variations, the criterion used was to maintain the analysis of the dates on which at least 5 transactions were carried out.

\section{RESULTS AND DISCUSSION}

Comparing the estimates of the average liquidity costs provided by the five models and the average quoted bid-ask spread (AQS), we observe that the Choi, Salandro and Shastri (CSS) model had the best performance among all models, for the corn futures contracts traded both at B3 and CBOT (Chart 1). Similar results were obtained by Shah, Brorsen, and Anderson (2012) in their study of wheat contracts at the Kansas City Stock Exchange. 
Chart 2 reports the correlation between the liquidity costs estimated using the five models and the quoted bid-ask spread. The correlation analysis suggests that for the contracts traded at the Chicago Board of Trade, the RM and CDP models were the ones that presented the highest correlations with the quoted bid-ask spread (AQS). On the other hand, for the contracts traded at B3, the CFTC and TW models were the ones that exhibited the highest correlation with the quoted bid-ask spread.

\section{(Chart 1)}

DESCRIPTIVE STATISTICS RELATED TO THE BID-ASK SPREAD

\begin{tabular}{rlccccccc}
\hline & & RM & CSS & CDP & TW & RM & CFTC & AQS \\
\hline \multirow{3}{*}{ CBOT } & Mean & 0,0183 & 0,0217 & 0,0185 & 0,0317 & 0,0183 & 0,0181 & 0,0247 \\
\cline { 2 - 9 } & SD & 0,0135 & 0,0159 & 0,0138 & 0,0088 & 0,0135 & 0,0133 & 0,0034 \\
\cline { 2 - 9 } & CV & $73,87 \%$ & $73,15 \%$ & $74,59 \%$ & $27,81 \%$ & $73,87 \%$ & $73,45 \%$ & $13,81 \%$ \\
\hline \multirow{3}{*}{ B3 } & Mean & 0,1122 & 0,1281 & 0,1085 & 0,0709 & 0,1122 & 0,0608 & 0,1599 \\
\cline { 2 - 9 } & SD & 0,1827 & 0,2087 & 0,1381 & 0,0877 & 0,1827 & 0,0643 & 0,1980 \\
\cline { 2 - 9 } & CV & $162,77 \%$ & $162,93 \%$ & $127,30 \%$ & $123,69 \%$ & $162,77 \%$ & $105,71 \%$ & $123,84 \%$ \\
\hline
\end{tabular}

* RM stands for Roll model; CSS stands for the Choi, Salandro, and Shastri model; CDP stands for Chu, Ding, and Pyun model; TW stands for the Thompson and Walley model; CFTC stands for the Wang, Yau, and Baptiste model and AQS stands for the Absolute Quoted Spread.

Source: Elaborated by the authors.

\section{(Chart 2)}

CORRELATION COEFFICIENTS BETWEEN THE BID ASK SPREAD ESTIMATES, FOR B3 MARKETS (BOTTOM) AND FOR CBOT MARKETS (TOP)

\begin{tabular}{lcccccc}
\hline & AQS & ROLL & CDP & CSS & TW & CFTC \\
\hline AQS & & 0,730 & 0,780 & 0,678 & 0,680 & 0,602 \\
\hline ROLL & 0,170 & & 0,998 & 0,907 & 0,867 & 0,800 \\
\hline CDP & 0,287 & 0,995 & & 0,908 & 0,859 & 0,790 \\
\hline CSS & 0,210 & 0,941 & 0,915 & & 0,818 & 0,735 \\
\hline TW & 0,460 & 0,367 & 0,562 & 0,337 & & 0,850 \\
\hline CFTC & 0,560 & 0,340 & 0,344 & 0,267 & 0,626 & \\
\hline
\end{tabular}

* ROLL stands for Roll model; CSS stands for the Choi, Salandro, and Shastri model; CDP stands for Chu, Ding, and Pyun model; TW stands for the Thompson and Walley model; CFTC stands for the Wang, Yau, and Baptiste model and AQS stands for the Absolute Quoted Spread. 
Comparing the results found for the two exchanges, we verified that the liquidity costs for the CBOT corn futures market hovers around 2 and 3 cents (in $\mathrm{R} \$ / \mathrm{bag}$ ), which converted to the reference standard of this exchange represents between one and two times the value of the minimum trading tick (US\$ 0.25/bushel). Similar results were found by Wang, Garcia, and Irwin (2013). In a broader perspective, it can be classified as a low liquidity cost. On the other hand, trading volume registered at B3 is approximately five times lower than that observed at CBOT. It is reasonable to suggest that both the lower volume of trading and the distribution of the bid-ask spread during the trading day or between different trading days, make the B3's liquidity cost higher (Wang \& Yau, 2000; Wang, Garcia, \& Irwin, 2013), as well as large fluctuations over time (Graph 1).

\section{(Graph 1) \\ QUOTED BID-ASK SPREAD OBSERVED AT B3 AND CBOT CORN FUTURES MARKETS, IN PERCENTAGE TERMS, DAILY SERIES}

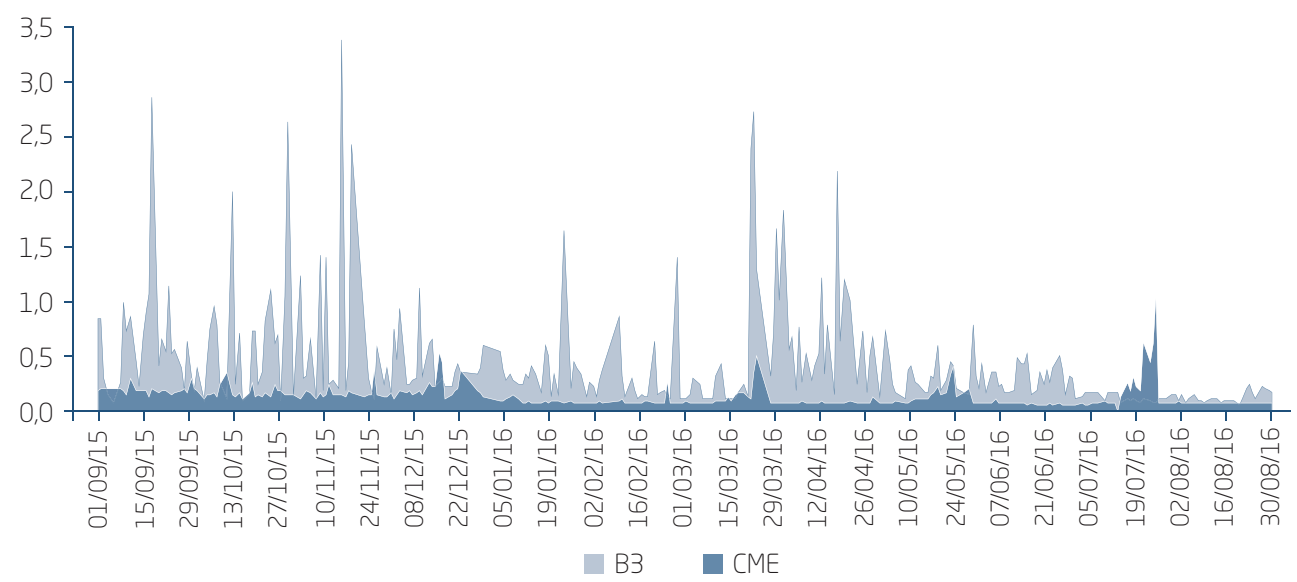

* In order to capture abrupt oscillations in the bid-ask spread, we used daily series composed of the maximum values and compared between the different maturities.

Source: Elaborated by the authors.

Analyzing the corn futures contracts traded at B3, we observe a large amplitude in the estimated bid-ask spreads. Our estimates ranged between 6 and 18 cents (in $\mathrm{R} \$ / \mathrm{bag}$ ), and most models underestimate the quoted bid-ask spread (AQS). It should be noted that the models based on absolute price variation (TW and CFTC) were the ones with the lowest spread values (Chart 1). One possible reason for that is related to the lower bias in the 
TW and similar models, as discussed by Otsubo (2015). Therefore, in a market with relatively lower liquidity levels (B3), restrictive assumptions, such as the ones required by the CFTC model (which imposes the need for inversion of values), tend to reduce the information content, what ultimately contributes to make the estimated bid-ask spread more distant from the quoted bid-ask spread.

On the other hand, when analyzing the corn futures contracts traded at CBOT, we verify that the models based on price covariance are more sensitive to abnormal market conditions. Throughout most of the period of analysis, the models based on price covariance orbit around the quoted bid-ask spread, ranging between the estimated values given by the CFTC and TW models (Graph 2). However, in July 2016, we observe a reduction in liquidity levels related to the July contract (C N06) when the liquidity costs accounted for $1 \%$ of the value of the future contract in the CME (Graph 1). The RM, CSS and CDP models presented a distinct behavior in this period, being influenced by the specific situation of the market.

\section{(Graph 2)}

\section{BID-ASK SPREAD ESTIMATES FOR THE CORN CONTRACTS TRADED AT CBOT, MONTHLY AVERAGES}

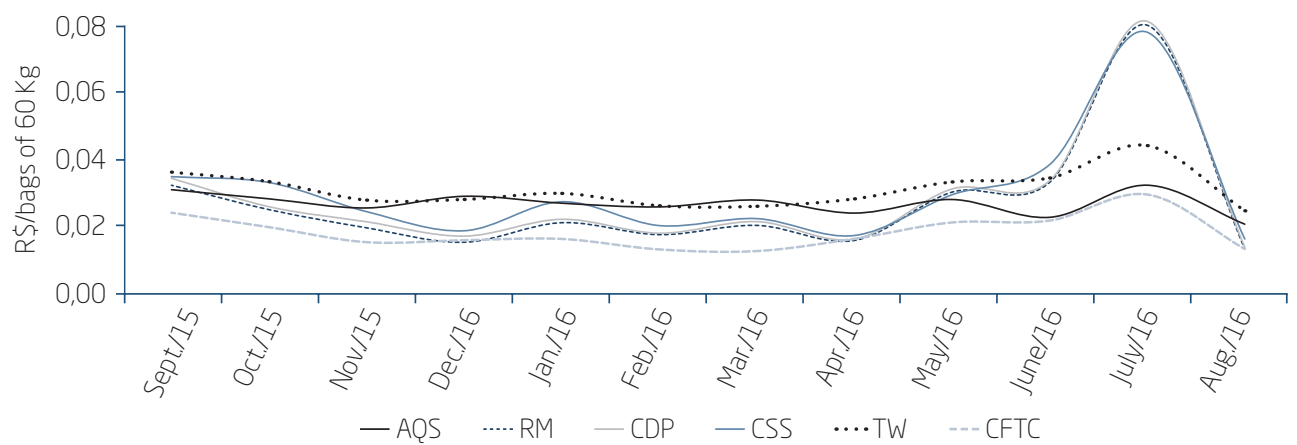

* RM stands for Roll model; CSS stands for the Choi, Salandro, and Shastri model; CDP stands for Chu, Ding, and Pyun model; TW stands for the Thompson and Walley model; CFTC stands for the Wang, Yau, and Baptiste model and AQS stands for the Absolute Quoted Spread.

Source: Elaborated by the authors.

For the corn futures contracts at B3, the two groups of models for bidask spread estimation had different behaviors. Given the lower liquidity levels of the contracts traded on this stock exchange, a smaller share of the observations is composed of price changes, and price reversion happens frequently. This fact causes the TW and CFTC models to show very close 
results, both presenting slightly lower values than the quoted bid-ask spread (Graph 3).

\section{(Graph 3)}

\section{BID-ASK SPREAD ESTIMATES FOR THE CORN CONTRACTS AT B3, MONTHLY AVERAGES}

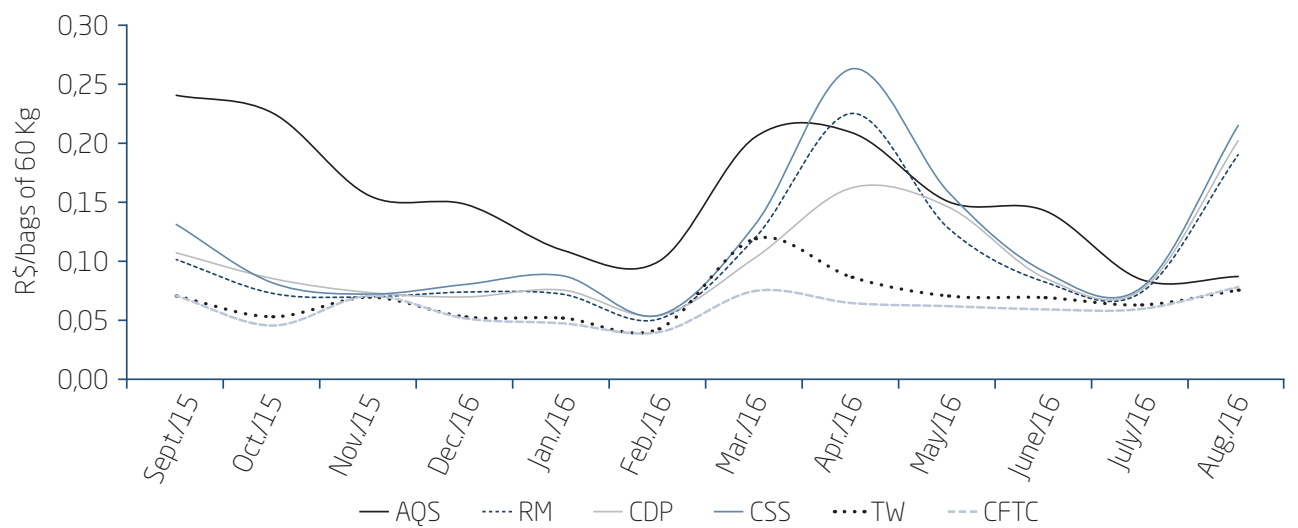

* RM stands for Roll model; CSS stands for the Choi, Salandro, and Shastri model; CDP stands for Chu, Ding, and Pyun model; TW stands for the Thompson and Walley model; CFTC stands for the Wang, Yau, and Baptiste model and AQS stands for the Absolute Quoted Spread.

Source: Elaborated by the authors.

The models based on price covariance seem to capture changes in the market in times of high liquidity costs better, as observed in the period between March and April 2016, where quoted bid-ask spreads for the July 2016 maturity accounted for $2.5 \%$ of the contract value (Graph 1). In November 2015, quoted bid-ask spreads for the May 2016 contract accounted for $3.3 \%$ of the contract value, but given the lower dispersion of spreads observed in this period, no models caught this anomaly.

We also analyzed the bid-ask spread according to contract maturity, based on segregation using different time windows. The strategy was to delimit the period close to maturity, that is, the first fortnight of negotiation in the month of maturity (from 0 to 15 days), the previous month of negotiation before the contract expired (from 16 to 45 days) and so on, contemplating the bid-ask spread analysis up to 3 months before the contract expires (Chart 2).

In general, we observe an increase in the bid-ask spread as maturity approaches, thus pointing to the existence of a calendar effect in the CBOT corn futures market (Chart 3). This increase is greater as the liquidity levels 
observed related to the contract decrease (July 2016). According to Wang, Garcia, and Irwin (2013), the increase in the bid-ask spread in the days before maturity is due to the decrease in the volume of negotiations, since the agents operating in the market liquidate their positions to avoid physical delivery.

\section{(Chart 3)}

\section{BID-ASK SPREAD ESTIMATES FOR THE CORN CONTRACTS TRADED AT CBOT, ACCORDING TO MATURITY}

\begin{tabular}{|c|c|c|c|c|c|c|c|}
\hline Maturity & Time Window & $\mathrm{RM}$ & $\mathrm{CDP}$ & CSS & TW & CFTC & AQS \\
\hline \multirow{4}{*}{ C Z05 } & 75 to 100 days & 0,0146 & 0,0147 & 0,0148 & 0,0346 & 0,0170 & 0,0234 \\
\hline & 46 to 75 days & 0,0157 & 0,0159 & 0,0151 & 0,0341 & 0,0152 & 0,0230 \\
\hline & 16 to 45 days & 0,0143 & 0,0143 & 0,0125 & 0,0312 & 0,0138 & 0,0232 \\
\hline & 0 to 15 days & 0,0113 & 0,0133 & 0,0143 & 0,0451 & 0,0275 & 0,0514 \\
\hline \multirow{4}{*}{$\mathrm{CHOG}$} & 75 to 100 days & 0,0138 & 0,0142 & 0,0156 & 0,0204 & 0,0090 & 0,0230 \\
\hline & 46 to 75 days & 0,0103 & 0,0109 & 0,0127 & 0,0217 & 0,0112 & 0,0240 \\
\hline & 16 to 45 days & 0,0115 & 0,0115 & 0,0123 & 0,0194 & 0,0076 & 0,0245 \\
\hline & 0 to 15 days & 0,0455 & 0,0498 & 0,0420 & 0,0426 & 0,0273 & 0,0654 \\
\hline \multirow{4}{*}{ C K06 } & 75 to 100 days & 0,0202 & 0,0204 & 0,0229 & 0,0299 & 0,0115 & 0,0242 \\
\hline & 46 to 75 days & 0,0168 & 0,0169 & 0,0192 & 0,0220 & 0,0068 & 0,0219 \\
\hline & 16 to 45 days & 0,0171 & 0,0171 & 0,0176 & 0,0250 & 0,0141 & 0,0229 \\
\hline & 0 to 15 days & 0,0747 & 0,0767 & 0,0681 & 0,0611 & 0,0535 & 0,0543 \\
\hline \multirow{4}{*}{ C N06 } & 75 to 100 days & 0,0079 & 0,0079 & 0,0094 & 0,0241 & 0,0129 & 0,0222 \\
\hline & 46 to 75 days & 0,0143 & 0,0146 & 0,0144 & 0,0240 & 0,0133 & 0,0215 \\
\hline & 16 to 45 days & 0,0321 & 0,0324 & 0,0369 & 0,0306 & 0,0202 & 0,0220 \\
\hline & 0 to 15 days & 0,1113 & 0,1125 & 0,1057 & 0,0953 & 0,0698 & 0,0872 \\
\hline \multirow{3}{*}{ C U06 } & 75 to 100 days & 0,0380 & 0,0382 & 0,0455 & 0,0332 & 0,0208 & 0,0233 \\
\hline & 46 to 75 days & 0,0367 & 0,0373 & 0,0483 & 0,0284 & 0,0179 & 0,0223 \\
\hline & 16 to 45 days & 0,0134 & 0,0135 & 0,0179 & 0,0207 & 0,0119 & 0,0215 \\
\hline
\end{tabular}

* Contract maturities: C Z05 refers to December 2015; C H06 refers to Mach 2016; C K06 refers to May 2016; C N06 refers to July 2016, and C U06 refers to September 2016. 
For the corn futures contracts traded at B3, the increase in the bid-ask spread as maturity approaches is not widely observed. However, when analyzing the 16 to 45 days window prior to contract expiration, it is possible to notice an increase in the bid ask spread for the May 2016 contract (C K06). A similar situation occurs with the July 2016 contract for the 46 to 75 days window (Chart 3).

\section{(chart 4)}

BID-ASK SPREAD ESTIMATES FOR THE CORN CONTRACTS TRADED AT B3, ACCORDING TO MATURITY

\begin{tabular}{|c|c|c|c|c|c|c|c|}
\hline Maturity & Time Window & RM & CDP & CSS & TW & CFTC & AQS \\
\hline \multirow{4}{*}{ C ZO5 } & 75 to 100 days & 0,0749 & 0,0780 & 0,0869 & 0,0587 & 0,0512 & 0,1215 \\
\hline & 46 to 75 days & 0,0847 & 0,0973 & 0,0851 & 0,0513 & 0,0492 & 0,0878 \\
\hline & 16 to 45 days & 0,0429 & 0,0441 & 0,0453 & 0,0409 & 0,0381 & 0,0677 \\
\hline & 0 to 15 days & 0,0396 & 0,0416 & 0,0505 & 0,0410 & 0,0345 & 0,0696 \\
\hline \multirow{4}{*}{$\mathrm{CHOG}$} & 75 to 100 days & 0,1298 & 0,1446 & 0,1862 & 0,0849 & 0,1031 & 0,3977 \\
\hline & 46 to 75 days & 0,0601 & 0,0643 & 0,0844 & 0,0585 & 0,0292 & 0,3538 \\
\hline & 16 to 45 days & 0,0698 & 0,0755 & 0,0790 & 0,0747 & 0,0895 & 0,1986 \\
\hline & 0 to 15 days & 0,1384 & 0,1320 & 0,1664 & 0,0488 & 0,0444 & 0,1128 \\
\hline \multirow{4}{*}{ CKO6 } & 75 to 100 days & 0,0624 & 0,0633 & 0,0756 & 0,0492 & 0,0472 & 0,0837 \\
\hline & 46 to 75 days & 0,0545 & 0,0557 & 0,0531 & 0,0493 & 0,0511 & 0,0993 \\
\hline & 16 to 45 days & 0,1462 & 0,1756 & 0,1521 & 0,1837 & 0,2650 & 0,4230 \\
\hline & 0 to 15 days & 0,0681 & 0,0626 & 0,0552 & 0,0770 & 0,1175 & 0,3306 \\
\hline \multirow{4}{*}{ CNO6 } & 75 to 100 days & 0,5241 & 0,3962 & 0,6905 & 0,1461 & 0,1054 & 0,4365 \\
\hline & 46 to 75 days & 0,2779 & 0,3120 & 0,3752 & 0,0790 & 0,0688 & 0,1854 \\
\hline & 16 to 45 days & 0,0822 & 0,0850 & 0,0832 & 0,0697 & 0,0579 & 0,1336 \\
\hline & 0 to 15 days & 0,0701 & 0,0719 & 0,0707 & 0,0720 & 0,0458 & 0,1215 \\
\hline \multirow{3}{*}{ CU06 } & 75 to 100 days & 0,0618 & 0,0627 & 0,0679 & 0,0502 & 0,0391 & 0,0725 \\
\hline & 46 to 75 days & 0,0442 & 0,0448 & 0,0457 & 0,0473 & 0,0427 & 0,0674 \\
\hline & 16 to 45 days & 0,1493 & 0,1520 & 0,1601 & 0,0652 & 0,0643 & 0,0872 \\
\hline
\end{tabular}

* Contract maturities: C Z05 refers to December 2015; C H06 refers to Mach 2016; C K06 refers to May 2016; C N06 refers to July 2016, and C U06 refers to September 2016. 
In both cases, the calendar effect related to contract expiry is replaced by the rollover effect. In the latter case, market participants take advantage of the periods of greater liquidity in each contract to avoid the incidence of higher liquidity costs caused by the closure of the contract. When analyzing the corn contracts traded at B3 according to their maturity, we observe that the models used underestimate the quoted bid-ask spread during most of the analyzed period.

Chart 4 also allows a seasonal analysis, which is quite relevant in agricultural markets. The highest bid-ask spread values were recorded at B3 for the following contracts: March (C H06), May (C K06) and July (C N06). According to Mattos and Silveira (2015), it is during the first half of the year that the first corn crop is harvested (between February and May). The second corn harvest is concentrated in July and August. Therefore, it should be noted that two out of the three analyzed contracts with the highest bid-ask spread are within the harvest period.

\section{CONCLUSIONS}

In order to estimate the liquidity costs related to agricultural futures contracts in situations where there is absence or shortage of intraday information, the literature has used implicit bid-ask spread models. In this context, the present study aimed to estimate and compare the liquidity costs for the corn futures markets in B3 and CBOT, using five bid-ask spread estimation models, from September 2015 to August 2016.

Estimates of bid-ask spread based on price covariance (ROLL, CSS, CDP) and estimates based on absolute price variation (TW and CFTC) captured some particularities of B3 and CBOT corn futures markets. However, none of these models performed considerably better than the others. Regarding corn futures market at CBOT, the measures based on price covariance were more influenced by atypical market situations (July 2016) and in general, all models showed some sort of calendar effect, in which there is an increase in liquidity costs levels in the market within 15 days to maturity.

Regarding corn futures markets at B3, the models generally underestimate the quoted bid-ask spread, and only under conditions of persistence of high spreads, such as the one occurred in April 2016, there was an overvaluation of the spread. One of the consequences of the lower liquidity levels related 
to the B3 corn futures market is the occurrence of spikes in the bid-ask spread behavior. This fact creates an additional challenge to identify the liquidity cost of the contracts being traded. The lower trading volume registered at B3 is also responsible for the uneven distribution of the trades over a trading day, including the existence of non-trading periods. Such a scenario may create a biased reference to intraday volatility, thus, affecting the measurement of the bid-ask spread.

Another peculiarity of B3 corn markets is that only in the most liquid contracts (March and September), there is an increase in the liquidity cost as maturity approaches. For other contracts, it may be the case of anticipated liquidation or hedge rollover. Despite of the growing liquidity of the corn futures markets at B3, the Brazilian corn market still represents a small share of the global market (about $9 \%$ of the world production), a fact that inhibits the participation of international players. Given the peculiarities of the domestic market, such as the presence of two annual harvests, domestic market participants seek alternative solutions, such as anticipation of the liquidation or hedge rollover to overcome the high liquidity costs in this market.

Among the results, it should be noted that the inverse relationship between volume and liquidity costs (proxied by the bid-ask spread) is widely observed and documented in the literature (Wang \& Yau 2000; Martinez et al., 2011; Shah, Brorsen, \& Anderson 2012; Wang, Garcia, \& Irwin 2013). Thus, we also observe a higher trading volume and lower liquidity cost at CBOT, if compared to B3.

Finally, bid-ask spread models based on covariance or absolute price changes are useful especially for markets with relatively low liquidity or thin markets. As a suggestion for subsequent studies, we suggest comparing the bid-ask spread estimates between thin markets, seeking to capture the intrinsic characteristics of these markets. We also suggest expanding the scope of commodities analyzed, incorporating analysis on the nature of commodities (stock, non-stock, metals, energy, among others). As limitations of the study, to operate the methodologies chosen in the present study, periods without transactions were excluded. However, there is a need to understand better how these periods of inactivity in the trading sessions affect the formation of bid-ask spread, what is particularly useful for emerging and thin markets. 


\section{REFERENCES}

Admati, A. R., \& Pfleiderer, P. (1988). A theory of intraday patterns: volume and price variability. The Review of Financial Studies, 1 (1), 3-40. doi 10.1093/ $\mathrm{rfs} / 1.1 .3$

Bryant, H. L., \& Haigh, M. S. (2004). Bid-ask spreads in commodity futures markets. Applied Financial Economics, 14(13), 923-936. doi 10.1080/09603 10042000284669

Choi, J. Y., Salandro, D., \& Shastri, K. (1988). On the estimation of Bid-ask spreads: Theory and evidence. The Journal of Financial and Quantitative Analysis, 23(2), 219-230. doi 10.2307/2330882

Chu, Q. C., Ding, D. K., \& Pyun, C. S. (1996). Bid-ask bounce and spreads in the foreign exchange futures market. Review of Quantitative Finance and Accounting, 6(1), 19-37. doi 10.1007/BF00290794

Demsetz, H. (1968). The cost of transacting. Quarterly Journal of Economics, 82(1), 33-53. doi 10.2307/1882244

Eaves, J., \& Williams, J. (2010). Are intraday volume and volatility U-shaped after accounting for public information? American Journal of Agricultural Economics, 92(1), 1-16. doi 10.1093/ajae/aap007

Foster, F. D., \& Viswanathan, S. (1990). A theory of the interday variations in volume, variance, and trading costs in securities markets. The Review of Financial Studies, 3(4), 593-624. doi 10.1093/rfs/3.4.593

Frank, J., \& Garcia, P. (2011). Bid-ask spreads, volume and volatility: Evidence from livestock markets. American Journal of Agricultural Economics, 93 (1), 209-225. doi 10.1093/ajae/aaq116

Gaudenzi, B., Zsidisin, G. A., Hartley, J. L., \& Kaufmann, L. (2017). An exploration of factors influencing the choice of commodity price risk mitigation strategies. Journal of Purchasing \& Supply Management. doi 10.1016/j.pursup.2017.01.004

Irwin, S. H., \& Sanders, D. R. (2012). Financialization and structural change in commodity futures markets. Journal of Agricultural and Applied Economics, 44(3), 371-396. doi 10.1017/S1074070800000481

Kyle, A. S. (1985). Continuous auctions and insider trading. Econometrica, 53(6), 1315-1335. doi 10.2307/1913210

Lee, C., \& Ready, M. J. (1991). Inferring trade direction from intraday data. The Journal of Finance, 46(2), 733-746. doi 10.1111/j.1540-6261.1991.tb 02683.x 
Lehecka, G. V., Wang, X., \& Garcia, P. (2014). Gone in ten minutes: Intraday evidence of announcement effects in the electronic corn futures markets. Applies Economic Perspectives and Policy, 36(3), 504-526. doi 10.1093/aepp/ ppu010

Marquezin, C. L. (2013). Custo de liquidez do contrato futuro de soja na BM\&F-Bovespa, no período de 2010 a 2013 (Master's thesis). Universidade Federal de Viçosa, Minas Gerais, MG, Brazil. Retrieved from http://www. locus.ufv.br/handle/123456789/81

Marquezin, C. L., \& Mattos, L. B. de. (2014). Custo de liquidez do contrato futuro de boi gordo da BM\&FBovespa. Revista de Administração Mackenzie, 15(4), 164-192. doi 10.1590/1678-69712014/administracao.v15n4p164-192

Martinez, V., Gupta, P., Tse, Y., \& Kittiakarasakun, J. (2011). Electronic versus open outcry trading in agricultural commodities futures markets. Review of Financial Economics, 20(1), 28-36. doi 10.1016/j.rfe.2010.09.001

Mattos, F., \& Silveira, R. (2015). Futures price response to crop reports in grain markets. The Journal of Futures Markets, 36 (10), 923-942. doi 10.1002/ fut. 21764

Michaely, R., \& Vila, J.-L. (1996). Trading volume with private valuation: Evidence from the ex-dividend day. Review of Financial Studies, 9(2), 471-509. doi 10.1093/rfs/9.2.471

Otsubo, Y. (2015). Measuring the bid-ask spreads: A note on the potential downward bias of the Thompson-Waller estimator. Applied Economics Letters, 22(10), 808-814. doi 10.1080/13504851.2014.978071

Roll, R. (1984). A simple implicit measure of the effective Bid-ask spread in an efficient market. The Journal of Finance, 39(4), 1127-1139. doi 10.1111/ j.1540-6261.1984.tb03897.x

Shah, S., \& Brorsen, B. W. (2011). Electronic versus open outcry: Side-by-side trading of KCBT wheat futures. Journal of Agricultural and Resource Economics, 36(1), 48-62. Retrieved from http://www.jstor.org/stable/ 23243133

Shah, S., Brorsen, B. W., \& Anderson, K. B. (2012). Effective bid-ask spread in futures versus futures options. Journal of Agricultural and Resource Economics, 37(3), 455-468. Retrieved from http://www.jstor.org/stable/ 23496727

Subrahmanyam, A. (1991). Risk aversion, market liquidity, and price efficiency. The Review of Financial Studies, 4(3), 417-441. doi 10.1093/rfs/ 4.3.417

Thompson, S., Eales, J. S., \& Seibold, D. (1993). Comparison of liquidity costs between the Kansas City and Chicago wheat futures contracts. Journal of Agricultural and Resource Economics, 185-197. Retrieved from http://www. jstor.org/stable/40986791 
Thompson, S., \& Waller, M. L. (1987). The execution cost of trading in commodity futures markets. Food Research Institute Studies, 20(2), 141-163.

Wang, G. H. K., Yau, J., \& Baptiste, T. (1997). Trading volume and transaction costs in futures markets. The Journal of Futures Markets, 17(7), 757-780. doi 10.1002/(SICI) 1096-9934(199710) 17:7<757::AID-FUT2>3.0.CO;2-M

Wang, G. H. K., \& Yau, J. (2000). Trading volume, bid-ask spread, and price volatility in futures markets. The Journal of Futures Markets, 20(10), 943-970. doi 10.1002/1096-9934(200011)20:10<943::AID-FUT4>3.0.CO;2-8

Wang, X., Garcia, P., \& Irwin, S. H. (2013). The behavior of bid-ask spread in the electronically traded corn futures market. American Journal of Agricultural Economics, 96(2), 557-577. doi 10.1093/ajae/aat096

Wood, R. A., Mcinish, T. H., \& Ord, J. K. (1985). An investigation of transactions data for NYSE stocks. The Journal of Finance, 40(3), 723-739. doi 10.1111/ j.1540-6261.1985.tb04996.x

\section{ABOUT THE AUTHORS}

\section{JULYERME MATHEUS TONIN}

$\mathrm{PhD}$ student in Applied Economics (with PDSE scholarship sandwich, Évora University), Universidade de São Paulo (USP).

Assistant Professor at the Department of Economics,

Universidade Estadual de Maringá (UEM).

Avenida Colombo, 5790, Cidade Universitária, Maringá - PR - Brazil - CEP 87020-900

E-mail: jmtonin@uem.br

\section{GERALDO COSTA JUNIOR}

$\mathrm{PhD}$ student in Applied Economics in Applied Economics,

Universidade de São Paulo (USP).

Assistant Professor at the Accounting Department,

Universidade Federal Fluminense (UFF).

Avenida Aluizio da Silva Gomes, Cavaleiros - Macaé - RJ - Brazil - CEP 27930560

E-mail: geraldocjr@gmail.com

\section{JOÃO GOMES MARTINES FILHO}

$\mathrm{PhD}$ in Applied Economics from the Department of Economy,

Ohio State University.

Professor at the Postgraduate Program in Applied Economics,

Universidade de São Paulo (USP).

Avenida Padua Dias, 11 - Piracicaba - SP - Brazil - CEP 13418-900

E-mail: martines@usp.br 